\title{
Study of the Determinants of the Use of Breast Cancer Screening in Women 35 to 65 Years in the Region of Thies (Senegal)
}

\author{
Jean Augustin Diegane Tine ${ }^{1,2}$, Khadim Niang1,2, Adanminakou Samiratou ${ }^{1,2}$, \\ Adama Faye ${ }^{1,2}$, Anta Tal Dia ${ }^{1,2}$ \\ ${ }^{1}$ Department of Preventive Medicine and Public Health, Cheikh Anta Diop University, Dakar, Senegal \\ ${ }^{2}$ Institute of Health and Development (ISED), UCAD, Dakar, Senegal \\ Email: leki105@yahoo.fr, diegantin@gmail.com
}

How to cite this paper: Tine, J.A.D., Niang, K., Samiratou, A., Faye, A. and Dia, A.T. (2018) Study of the Determinants of the Use of Breast Cancer Screening in Women 35 to 65 Years in the Region of Thies (Senegal). Open Journal of Epidemiology, 8, 201-212.

https://doi.org/10.4236/ojepi.2018.84016

Received: July 25, 2018

Accepted: October 20, 2018

Published: October 23, 2018

Copyright $\odot 2018$ by authors and Scientific Research Publishing Inc. This work is licensed under the Creative Commons Attribution International License (CC BY 4.0).

http://creativecommons.org/licenses/by/4.0/

(c) (i) Open Access

\begin{abstract}
Introduction: In Senegal, breast cancer is the second most common cancer of women after cervical cancer. It is a cancer accessible to clinical and radiological screening. The objective of this study was to study the determinants of the use of breast cancer screening among women aged 35 to 65 in the Thies region in 2015. Material and Methods: It was a descriptive and analytical cross-sectional study. It was conducted with a sample of women selected using a two-stage cluster survey. The study used a questionnaire to collect data on the individual characteristics of women, knowledge, attitudes and practice on breast cancer and quality of care in an individual interview at the homes of women after consent. The data was entered on the Epi Info 3.5.3 software and analyzed with the R 3.3.3 software. A description of qualitative variables across proportions and quantitative variables by mean and standard deviation was performed. Parametric or non-parametric tests were used to examine the association between the dependent variable (breast cancer screening) and explanatory variables (predisposing factors, resources, health needs) according to their applicability conditions and at a risk $\alpha$ equal $5 \%$. Finally, all variables with $\mathrm{p}$ less than 0.25 were used to construct an explanatory model by simple logistic regression. Results: The study involved 960 women aged 35 to 65 years. The average age was 43.8 years with a standard deviation of 8.3 years. The rate of breast cancer screening was $25.7 \%$. Educated women (OR adjusted $=1.89[1.25-2.85]$ ), women who resided in urban settings (adjusted $\mathrm{OR}=1.79[1.05-3.04])$, those who experienced at least one risk factor for breast cancer $(\mathrm{OR}$ adjusted $=2.71[1.81-4.06]$ ) were more likely to use screening breast cancer. In contrast, women with low socioeconomic status (adjusted OR $=0.66[0.45-0.97]$ ) were less likely to be screened. Conclusion: Level of education, knowledge of breast cancer and having received screening
\end{abstract}


advice are factors to consider in improving the rate of breast cancer screening in Thies, and the most important remains public awareness.

\section{Keywords}

Cancer Breast, Screening, Determinant, Senegal

\section{Introduction}

Breast cancer is the most common cancer among women worldwide and accounts for $16 \%$ of all female cancers [1]. It is the second most common cancer in the world (after lung cancer), affecting 1.7 million cases in 2012, or $11.9 \%$ of all cancers. The global incidence rate for breast cancer in 2012 is 34 cases per 100,000 population. This rate is 27.3 per 100,000 inhabitants in developing countries [2]. The incidence of breast cancer is rising in developing countries as a result of longer life expectancy, increased urbanization and the adoption of Western lifestyles [1]. Since the latest estimates for 2008, the incidence has increased by more than $20 \%$ and mortality by $14 \%$ [2].

Five-year breast cancer survival rates vary widely across countries, ranging from $80 \%$ or more in North America, Sweden, and Japan to nearly $60 \%$ in middle-income countries and less than $40 \%$ in low-income countries. The low survival rates in less developed countries can be explained mainly by the lack of early detection programs, which results in a high proportion of women with advanced disease, as well as the absence of appropriate diagnostic and treatment infrastructures [1].

In Senegal, breast cancer is the second most common cancer of women after cervix. It is a cancer accessible to clinical and radiological screening. This screening, if it is well conducted, makes it possible to establish an earlier diagnosis, thus optimizing treatment and thus reducing mortality. In several developed countries, there are already encouraging mass screening programs with mammography as the main tool. In Senegal, mammography is not very accessible to the population because of its high cost and the scarcity of imaging services. Given this economic context, common to developing countries, we rely on breast self-examination and clinical breast examination, which are simple, inexpensive and proven effective methods [3]. Although some risk reduction can be achieved through prevention, such strategies do not eliminate the majority of breast cancers that occur in lowand middle-income countries where the disease is diagnosed at steps very advanced. Therefore, early detection to improve the outcome of the disease and the chances of survival remains the main way to fight against breast cancer [1]. The age indicated for breast cancer screening varies by country, in Senegal it is indicated for women aged 35 to 65 years. The objective of this study is to identify the factors associated with the use of breast cancer screening in the female population of the Thies region in Senegal. 


\section{Methodology}

\subsection{Study Site}

Located $70 \mathrm{~km}$ from Dakar, the region of Thies is one of the 14 administrative regions of Senegal. It is located in the West of the country, in crown around the peninsula of Cape Verde. It covers an area of $6601 \mathrm{~km}^{2}$, or $3.4 \%$ of the national territory and is limited to the North by the region of Louga, to the South by the region of Fatick, to the East by the regions of Diourbel and Fatick and to the West by the region of Dakar and the Atlantic Ocean. According to data from the 2013 national demographic statistics, the population of Thiès is $1,788,864$ inhabitants. Thies is the second most urbanized region of Senegal after Dakar. With an urbanization rate of $48.8 \%$, it concentrates $14.3 \%$ of the urban population of Senegal. According to sex, the population is composed of $50.1 \%$ of men and $49.9 \%$ of women. The birth rate at the regional level is estimated at $34.1 \%$. In other words, on an average of 1000 inhabitants, there are 34 live births during the year. Thies is among the regions with the lowest mortality rate at $6.6 \%$, which is below the national average (7.7\%o) [4] [5].

\subsection{Type of Study}

This is a cross-sectional, descriptive and analytical study that took place in the Thies region from 17 to 30 August 2015.

\subsection{Population and Sampling}

The study population was represented by all the women residing in the Thies region.

To be included in this study, one must be a woman residing in Thies for at least three months and be between 35 and 65 years old. The criteria for non-inclusion were the non-consent of the woman and the absence during the investigation after two passages of the investigators.

The sample size was calculated by the Schwartz formula $\left(n=\left(\varepsilon^{2} \times p \times q\right) / i^{2}\right)$. With prevalence of breast cancer screening in women of reproductive age the p was not known, we chose $50 \%, \varepsilon=1.96$ and an accuracy of $4 \%$, the number is equal to 600 individuals. To minimize the cluster effect, we multiplied the result obtained by 1.5 , giving a population of 900 . Taking into account non-responses, we added $5 \%$ of the calculated size. This gives a corrected sample size of 948 women.

Finally, the sample size was 960 . A total of 48 clusters of 20 women were composed.

The two-stage cluster survey was conducted. The first step was to draw villages or neighborhoods to investigate. The second degree concerned the drawing of the concessions. Depending on the size of the population of the selected district or village, groups of concessions are formed. In each concession, the investigator interviewed all women who met the inclusion criteria. The selection of the following concessions was made with leaps of three. 


\subsection{Collection of Data}

The data collection was done by an individual interview with women aged 35 to 65 at their homes by interviewers.

The questionnaire was tested and validated during a pilot survey in Kaffrine. The investigators were trained in this questionnaire. The data collected focused on the personal characteristics of women, knowledge, attitudes and practices about breast quality and quality of care. The dependent variable was the use of breast cancer screening.

\subsection{Data Analysis}

The data was entered on the Epi Info 3.5.3 software. The data was analyzed with the R 3.3.3 software [6]. Qualitative variables were described with absolute and relative frequencies and quantitative variables by mean and standard deviation. Multivariate analysis was performed with a simple logistic regression for determination factors related to breast cancer screening, with adjustment independent variables ensuring the applicability conditions with a significance level set at $5 \%$. Variables with p less than 0.25 in bivariate analysis were used for modeling [7]. The lrtest (likelihood ratio) and AIC allowed the choice of the latter with the step-down method. Finally the test of Hosmer-Lemeshow tested the adequacy of the final model [8]. Associations were measured by odds ratios with their confidence intervals.

\subsection{Ethical Considerations}

Participation in this study was free. Free and informed consent was obtained from the women and any other person surveyed. A fact sheet was administered to each individual before signing the consent form. This study did not provide any compensation or compensation for those surveyed. The data collected remained confidential. The identity of the individuals who consented to participate was not mentioned on the collection tools. In all the uses of the results, anonymity has been respected.

\section{Results}

\subsection{Sociodemographic Characteristics of Women}

A total of 960 women were surveyed. The average age of women was $43.8( \pm 8.3)$ years with extremes ranging from 35 to 65 years. Each woman had an average of $4.2( \pm 2.3)$ children. Educated women accounted for $56.4 \%$ of our sample. Their level of schooling ranged from primary (33.1\%) to higher (1.8\%) and secondary (21.5\%). Married women accounted for about $82 \%$ of the workforce. The three-quarters of respondents lived in urban areas (see Table 1).

\subsection{Women's Knowledge of Breast Cancer}

Nine hundred and forty women, or $97.9 \%$, have heard of breast cancer. Nearly two-thirds of the respondents (65\%) knew at least one symptom that made them 
Table 1. Sociodemographic characteristics of the women surveyed $(n=960)$.

\begin{tabular}{|c|c|c|}
\hline Sociodemographic characteristics $(n=960)$ & $\begin{array}{c}\text { Frequency } \\
\text { absolute (n) }\end{array}$ & $\begin{array}{c}\text { Relative } \\
\text { frequency (\%) }\end{array}$ \\
\hline \multicolumn{3}{|l|}{ Instruction } \\
\hline Educated & 541 & 56.4 \\
\hline Uneducated & 419 & 43.6 \\
\hline \multicolumn{3}{|l|}{ Level of schooling } \\
\hline Not in school & 419 & 43.6 \\
\hline Primary & 318 & 33.1 \\
\hline Secondary & 206 & 21.5 \\
\hline Superior & 17 & 1.8 \\
\hline \multicolumn{3}{|l|}{ Marital status } \\
\hline Single & 34 & 3.5 \\
\hline Married & 785 & 81.8 \\
\hline Divorcee & 70 & 7.3 \\
\hline Widow & 71 & 7.4 \\
\hline \multicolumn{3}{|l|}{ Middle of residence } \\
\hline Urban & 768 & 80 \\
\hline Rural & 192 & 20 \\
\hline \multicolumn{3}{|l|}{ Socio-economic level } \\
\hline Poorer & 173 & 18 \\
\hline Poor & 319 & 33.2 \\
\hline Rich & 233 & 24.3 \\
\hline Richer & 235 & 24.5 \\
\hline \multicolumn{3}{|l|}{ Income generating activity } \\
\hline Yes & 577 & 60.1 \\
\hline No & 383 & 39.9 \\
\hline \multicolumn{3}{|l|}{ Time between residence and screening structure } \\
\hline Less than 15 minutes & 495 & 51.6 \\
\hline 15 to 60 minutes & 359 & 37.4 \\
\hline 60 minutes or more & 106 & 11 \\
\hline \multicolumn{3}{|l|}{ Women have benefited from screening $c$ Tips and Tricks } \\
\hline Yes & 285 & 29.7 \\
\hline No & 675 & 70.3 \\
\hline \multicolumn{3}{|l|}{ Background medico-gynecological } \\
\hline Yes & 361 & 37.6 \\
\hline No & 599 & 62.4 \\
\hline
\end{tabular}

suspect breast cancer. In the study, $28.3 \%$ of women knew at least one risk factor for the disease. More than half of the respondents (60.3\%) knew at least one 
means of breast cancer screening. Eight hundred and eighty-three women, or $92 \%$ of our study population, knew at least one breast cancer screening site (see Table 2).

\subsection{Attitudes of Women to Symptoms of Breast Cancer}

The study showed that $98.3 \%$ of respondents believe that in case of pain in the breast they would have gone to consult a health facility. Most women (96.3\%) believe that in the event of breast mass, they would have gone to a health facility for consultation. However 9 women or $0.9 \%$ would have consulted a traditional practitioner and 8 or $0.8 \%$ others would have used self-medication. Given an increase in breast volume, the majority of respondents (98\%) would have consulted in a health facility and only 2 or $0.2 \%$ would use self-medication. In case of discharge of the nipple, $92.9 \%$ of respondents believe that in this case they would have consulted in a health facility while 61 or $6.4 \%$ would not have worried. Nine hundred and forty-five women, or $98.5 \%$, think that, in the event of a change in the skin of the breast, they would have consulted in a health facility and only 2 or $0.2 \%$ would use self-medication (see Table 3 ).

\subsection{Use of Breast Cancer Screening}

The study showed that only 247 women, or $25.7 \%$ had previously used breast cancer screening against $74.3 \%$. The main reason for not using breast cancer screening is lack of knowledge (see Table 4).

Table 2. Women's knowledge of breast cancer $(n=960)$.

\begin{tabular}{ccc}
\hline Knowledge of breast cancer $(\mathbf{n}=960)$ & $\begin{array}{c}\text { Absolute } \\
\text { frequency (n) }\end{array}$ & $\begin{array}{c}\text { Frequency } \\
\text { relative (\%) }\end{array}$ \\
\hline Knowledge of the existence of breast cancer & 940 & 97.9 \\
Yes & 20 & 2.1 \\
No & & 65 \\
Knowledge of at least one symptom of breast cancer & 624 & 35 \\
Yes & 336 & 53.7 \\
No & & 46.3 \\
Breast pain & 335 & \\
Yes & 289 & 87.8 \\
No & & 12.2 \\
Mass at the breast & 548 & \\
Yes & 76 & 28.4 \\
No & & 71.6 \\
Nipple discharge & 189 & \\
Yes & & \\
No & & \\
Yes & & \\
Changing appearance of the breast skin & & \\
\hline
\end{tabular}




\section{Continued}

\begin{tabular}{|c|c|c|}
\hline No & 435 & 69.7 \\
\hline \multicolumn{3}{|c|}{ Axillary lymphadenopathy } \\
\hline Yes & 116 & 18.6 \\
\hline No & 508 & 81.4 \\
\hline \multicolumn{3}{|c|}{ Wound at the breast } \\
\hline Yes & 2 & 0.3 \\
\hline No & 622 & 99.7 \\
\hline \multicolumn{3}{|c|}{ Knowledge of at least one risk factor for breast cancer } \\
\hline Yes & 272 & 28.3 \\
\hline No & 688 & 71.7 \\
\hline \multicolumn{3}{|c|}{ Parity } \\
\hline Yes & 99 & 36.4 \\
\hline No & 173 & 63.6 \\
\hline \multicolumn{3}{|c|}{ Tobacco } \\
\hline Yes & 166 & 61 \\
\hline No & 106 & 39 \\
\hline \multicolumn{3}{|l|}{ Stress } \\
\hline Yes & 67 & 24.6 \\
\hline No & 205 & 75.4 \\
\hline
\end{tabular}

Keep silver coins in the bra

$\begin{array}{lcc}\text { Yes } & 25 & 9.2 \\ \text { No } & 247 & 90.8\end{array}$

Knowledge of at least one means of cancer screening

Yes

No

Self-examination

Yes

No

Mammography

Yes

No

Breast ultrasound

Yes

No

Knowledge of a screening site

Yes

No

Knowledge of the possibility of curing the disease

$$
\text { Yes }
$$

No 
Table 3. Attitude of women to symptoms of breast cancer $(n=960)$.

\begin{tabular}{|c|c|c|}
\hline Attitudes to symptoms of breast cancer $(n=960)$ & $\begin{array}{c}\text { Absolute } \\
\text { frequency (n) }\end{array}$ & $\begin{array}{c}\text { Relative } \\
\text { frequency (\%) }\end{array}$ \\
\hline \multicolumn{3}{|l|}{ In front of breast pain } \\
\hline Medical consultation & 943 & 98.3 \\
\hline Traditional healer & 5 & 0.5 \\
\hline Self-medication & 2 & 0.2 \\
\hline Inaction & 10 & 1 \\
\hline \multicolumn{3}{|l|}{ In front of a breast mass } \\
\hline Medical consultation & 924 & 96.3 \\
\hline Traditional healer & 9 & 0.9 \\
\hline Self-medication & 8 & 0.8 \\
\hline Inaction & 19 & 2 \\
\hline \multicolumn{3}{|l|}{ In front of a volume increase } \\
\hline Medical consultation & 940 & 98 \\
\hline Traditional healer & 7 & 0.7 \\
\hline Self-medication & 2 & 0.2 \\
\hline Inaction & 11 & 1.1 \\
\hline \multicolumn{3}{|l|}{ Before a discharge of the nipple } \\
\hline Medical consultation & 892 & 92.9 \\
\hline Traditional healer & 6 & 0.6 \\
\hline Self-medication & 1 & 0.1 \\
\hline Inaction & 61 & 6.4 \\
\hline \multicolumn{3}{|l|}{ In front of a change of the skin of the breast } \\
\hline Medical consultation & 945 & 98.5 \\
\hline Traditional healer & 6 & 0.6 \\
\hline Self-medication & 2 & 0.2 \\
\hline Inaction & 7 & 0.7 \\
\hline
\end{tabular}

Table 4. Action of breast cancer screening in women $(n=960)$.

\begin{tabular}{ccc}
\hline Use of breast cancer screening & $\begin{array}{c}\text { Absolute } \\
\text { frequency (n) }\end{array}$ & $\begin{array}{c}\text { Relative } \\
\text { frequency (\%) }\end{array}$ \\
\hline Breast cancer screening & 247 & 25.7 \\
Yes & 713 & 74.3 \\
Reason for non-screening for breast cancer & & 51 \\
Ignorance & 364 & 25.8 \\
Fear of knowing his status & 184 & 2.2 \\
No symptoms & 16 & 21 \\
Do not feel the need & 150 &
\end{tabular}




\subsection{Risk Factors Associated with Breast Screening for Women Aged 35 to 65}

The factors associated with the use of breast cancer screening in the women were searched by simple logistic regression. The final adjustment was made on education, area of residence, knowledge of risk factors, knowledge of self-examination, knowledge about healing, socioeconomic status, and counseling (see Table 5).

Educated women were 1.89 times more likely to be screened. Women living in urban areas were 1.79 times more likely to be screened than those living in rural areas. Women who knew at least one risk factor for breast cancer were 2.71 times more likely to use screening. Women who experienced breast self-examination were 8.42 times more likely to use breast cancer screening. Women who felt that breast cancer was curable were less likely to use screening $(\mathrm{OR}=0.34[0.23$ $0.50])$. Women with low socio-economic status were less likely to be screened $(\mathrm{OR}=0.66[0.45-0.97])$. Women who received counseling were 4.18 more likely to use screening.

Table 5. Factors associated with the use of breast cancer screening (simple logistic regression).

\begin{tabular}{|c|c|c|}
\hline Associated factors & Adjusted OR [95\% CI] & p-value \\
\hline \multicolumn{3}{|l|}{ Instruction } \\
\hline Non-educated & 1 & \\
\hline Educated & $1.89[1.25-2.85]$ & 0.002 \\
\hline \multicolumn{3}{|l|}{ Middle of residence } \\
\hline Rural & 1 & \\
\hline Urban & $1.79[1.05-3.04]$ & 0.032 \\
\hline \multicolumn{3}{|c|}{ Know at least one risk factor for breast cancer } \\
\hline No & 1 & \\
\hline Yes & $2.71[1.81-4.06]$ & $<0.001$ \\
\hline \multicolumn{3}{|c|}{ Knowledge of self-examination } \\
\hline No & 1 & \\
\hline Yes & $8.42[4.53-15.65]$ & $<0.001$ \\
\hline \multicolumn{3}{|c|}{ Knowledge of the possibility of curing the disease } \\
\hline No & 1 & \\
\hline Yes & $0.34[0.23-0.50]$ & $<0.001$ \\
\hline \multicolumn{3}{|l|}{ Socio-economic level } \\
\hline High & 1 & \\
\hline Low & $0.66[0.45-0.97]$ & $<0.001$ \\
\hline \multicolumn{3}{|c|}{ Woman having benefited from screening counseling } \\
\hline No & 1 & \\
\hline Yes & $4.18[2.81-6.23]$ & $<0.001$ \\
\hline
\end{tabular}




\section{Discussion}

The limit of this study is the lack of information on the quality and availability of the screening service. For a better understanding of the use of the breast cancer screening service, it is important to look for the cultural aspects of Thies populations.

The survey involved 960 women aged 35 to 65 from the Thies region. The breast cancer screening rate was $25.7 \%$ for these women at the time of the survey. The survey of knowledge attitudes and practices on breast cancer in a Senegalese female population, in 2009, showed a detection rate of $29 \%$ [3]. The prevalence of breast cancer screening appears to be low in the Thies region. This low rate could be related to a lack of awareness but also a consequence of the asymmetry of information in our health system because many women were able to benefit from a breast examination without knowing that it was about screening.

Our study found a statistically significant link between education and the use of breast cancer screening. Indeed, the prevalence of screening among educated women was almost twice the prevalence among the uneducated $(\mathrm{OR}=1.89[1.25$ - 2.85]). This result is similar to the study on the behavioral determinants of breast cancer screening in the United Arab Emirates in 2002 [9], also the same as the Nigerian study on knowledge, attitude and practice of women against breast cancer in $2006(\mathrm{OR}=3.56$ [2.58 - 4.92]) [10] and that of the Gueye study in Senegal in $2009(\mathrm{p}<0.001)$ [3]. In this sense, several hypotheses have been made according to which individuals who have benefited from formal education would give greater attention to health risks and the use of health services [11] [12] [13].

The place of residence was related to the use of screening. Women living in urban areas were more likely to use screening than rural women $(\mathrm{OR}=1.79$ [1.05 - 3.04]). This difference could be explained by the fact that urban centers are assimilated to areas of the rich and rural centers to those of the poor according to the socio-economic level. The women of the Thies region seem to know breast cancer well. In fact $97.9 \%$ of the women surveyed knew of the disease. The prevalence of screening was higher among women with at least one risk factor for breast cancer $(\mathrm{OR}=7.70[5.58-10.62])$. This can be explained by the fact that these women had a better knowledge of the risks that they incurred [12] [13].

The use of screening was strongly related to the knowledge of self-examination. Women who knew self-examination were 11 times more likely to have been tested. The self-examination was known by $69.3 \%$ of women. In 2009 , Gueye showed a self-awareness rate of $42.7 \%$ [3]. Women who perceived breast cancer to be curable were less likely to use screening $(\mathrm{OR}=0.34[0.23-0.50])$. This could be because these women consider breast cancer a benign disease, and for fear of being anxious to know they are sick when they are in apparent good health, they prefer to wait until the disease manifests itself to seek care [3] [14]. 
Women with low socio-economic status were less likely to be screened $(\mathrm{OR}=$ 0.66 [0.45 - 0.97]). Women with a good socioeconomic level have fewer financial constraints to access to care and to get tested than those with low socioeconomic status [14] [15].

The women who received screening counseling were more likely to get tested $(\mathrm{OR}=4.18$ [2.81 - 6.23]), hence the importance of women's awareness about managing their reproductive health General [3]. Mammography (14\%) and breast ultrasound (14.2\%) were cited as little screening tool by the women surveyed. to increase breast cancer screening rates, increase knowledge women on breast cancer and make screening technology accessible [16] [17] [18] [19].

\section{Conclusion}

Breast cancer is the second most common cancer in women in Senegal. It is important to emphasize secondary prevention knowing that primary prevention of breast cancer is not yet mastered. To do this, we must promote the early diagnostic disease through use of screening women at community level. This is conditioned by good knowledge of the populations about breast cancer, by equipment availability and accessibility of screening service.

\section{Conflicts of Interest}

The authors declare no conflicts of interest regarding the publication of this paper.

\section{References}

[1] World Health Organization (2018) Breast Cancer: Prevention and Fight against the Disease. http://www.who.int/topics/cancer/breastcancer/en/

[2] International Center for Research on Cancer (2013) Latest Global Statistics on Cancer. Press Release N 223. OMS, Geneva. https://www.iarc.fr/en/media-centre/pr/2013/pdfs/pr223_E.pdf

[3] Gueye, S.M.K., Bawa, K.D., Mbaye, M., Faye Dieme, M.E., Ba, M.G., Mendes, V., et al. (2009) Breast Cancer Screening: Knowledge and Practice of Breast Self-Examination in a Female Population in Senegal. Revue Médicale de Bruxelles, 30, 77-82.

[4] National Agency of Statistics and Demography (2015) Regional Economic and Social Situation 2013, Regional Service of Statistics and Demography Thiès, 139 p. http://www.ansd.sn/ressources/ses/SES-Thies-2013

[5] Region Medical of Thies (2013) Situation Socio-DHW area d e s thie area. http://udsmed.u-strasbg.fr/aufemo/PDF/actualites/SITUATION_RM_THIES.pdf

[6] R Core Team (2015) A Language and Environment for Statistical Computing. R Foundation for Statistical Computing, Vienna, Austria. http://www.r-project.org/

[7] Collet, D. (2003) Modeling Binary Data. CRC, London Chapman and Hall, 387 p.

[8] Hosmer, D.W. and Lemeshow, S. (1989) Applied Logistic Regression. John Wiley, New York, 307 p.

[9] Bener, A., Honein, G., Carter, A.O., Da'ar, Z., Miller, C. and Dunn, E.V. (2002) The Determinants of Breast Cancer Screening Behavior: A Focus Group Study of Women in the United Arab Emirates. Oncology Nursing Forum, 29, E91-E98. 
https://doi.org/10.1188/02.ONF.E91-E98

[10] Okobia, M.N., Bunker, C.H., Okonofua, F.E. and Osime, U. (2006) Knowledge, Attitude and Practice of Nigerian Women to Breast Cancer: A Cross-Sectional Study. World Journal of Surgical Oncology, 4, 11. https://doi.org/10.1186/1477-7819-4-11

[11] Duport, N., Ancelle-Park, R., Boussac-Zarebska, M., Uhry, Z. and Bloch, J. (2007) Membership Factors in Organized Breast Cancer Screening: FADO-Breast Study. "Screening for Cancers" Collection, 5 p.

[12] Hiatt, R.A., Klabunde, C., Breen, N., Swan, J. and Ballard-Barbash, R. (2002) Cancer Screening Practices from National Health Interview Surveys: Past, Present, and Future. Journal of the National Cancer Institute, 94, 1837-1846. https://doi.org/10.1093/jnci/94.24.1837

[13] Soler-Michel, P., Courtial, I. and Bremond, A. (2005) Reattendance of Women for Breast Cancer Screening Programs. A Review. Revue d'Epidémiologie et de Santé Publique, 53, 549-567. https://doi.org/10.1016/S0398-7620(05)84731-5

[14] Duport, N., Serra, D., Goulard, H. and Bloch, J. (2008) What Factors Influence the Practice of Screening for Female Cancers in France? Revue d'Epidémiologie et de Santé Publique, 56, 303-313. https://doi.org/10.1016/j.respe.2008.07.086

[15] Baudier, F., Michaud, C., Gautier, A. and Guilbert, P. (2007) Screening for Breast Cancer in France: Practices and Changing Habits in the Population of Women Aged 18 to 75, Health Barometer 2004-2005. BEH, 17, 142-144.

[16] Chamot, E., Charvet, A.I. and Perneger, T.V. (2007) Who Gets Screened, and Where: A Comparison of Organized and Opportunistic Mammography Screening in Geneva, Switzerland. European Journal of Cancer, 43, 576-584. https://doi.org/10.1016/j.ejca.2006.10.017

[17] Maxwell, C.J., Bancej, C.M. and Snider, J. (2001) Predictors of Mammography Use among Canadian Women Aged 50-69: Findings from the 1996/97 National Population Health Survey. CMAJ, 164, 329-334.

[18] Lagerlund, M., Hedin, A., Sparén, P., Thurfjell, E. and Lambe, M. (2000) Attitudes, Beliefs, and Knowledge as Predictors of Nonattendance in a Swedish Population-Based Mammography 67 Screening Program. Preventive Medicine, 31, 417-428. https://doi.org/10.1006/pmed.2000.0723

[19] Lostao, L., Joiner, T.E., Pettit, J.W., Chorot, P. and Sandín, B. (2001) Health Beliefs and Illness Attitudes as Predictors of Breast Cancer Screening. European Journal of Public Health, 11, 274-279. https://doi.org/10.1093/eurpub/11.3.274 